\title{
The Psychology of Leadership Selection: DiSC Results and Leadership Success in Health Care
}

\author{
Ronald M. Fuqua, Ph.D. \\ Associate Professor \\ Health Care Management, College of Health \\ Clayton State University \\ John Bryan, Ph.D. \\ Assistant Professor \\ Health Care Management, College of Health \\ Clayton State University
}

\begin{abstract}
Health care organizations seek successful leaders for their executive positions. Often, a psychologically-based assessment is used in an attempt to recognize factors that cannot easily be seen in applicants during the screening and selection process. There are a variety of assessments available for this purpose, each with its own approach and cost to administer. DiSC is one such instrument used for assessing traits of applicants. Using measures of Dominance, Influence, Steadiness, and Compliance, DiSC is currently used in business settings for the purpose of employee development and team building. Dr. William Marston, a physiological psychologist writing in the 1920s and 1930s, explored the meaning of normal human emotions by relating how a person perceives himself or herself in relation to the environment and describing how the person is likely to behave in response. However, it is questioned whether the assessments used, and the results they produce, can be associated with the success of the leader. In order to address this question, data on the results from the DiSC assessment for a small number of senior leaders of a health care organization is compared to their overall success in that organization. Granted that while the sample is small, 18, and the measures for success are not universal, there is some evidence to study. Other questions that arise are how do the traits of other organizational leaders compare to senior leadership traits, and are these traits indicators of their individual success. Effectively, in terms of success, does it pay to be like the boss or is it better to differ in your traits?
\end{abstract}

KEYWORDS: Leadership, psychological screening, DiSC,

\section{INTRODUCTION}

Health care organizations seek successful leaders for their executive positions. Often, a psychologically-based assessment is used in an attempt to recognize factors that cannot easily be seen in applicants during the screening and selection process. As Ryan and Ployhart (2014) state, "Over 100 years of psychological research on employee selection has yielded many advances, but the field continues to tackle controversies and challenging problems, revisit once-settled topics, and expand its borders." In fact, Diekmann and Konig (2015) review why people either love personality assessment, choose to leave it alone, or simply do not understand the results. Nonetheless, there are a variety of assessments available for this purpose, each with its own approach and cost to administer. DiSC is one such instrument used for assessing personality traits of applicants. Using measures of Dominance, Influence, 
Steadiness, and Compliance, DiSC is currently used in business settings for the purpose of employee development and team building. Dr. William Marston (1928), a physiological psychologist writing in the 1920s and 1930s, explored the meaning of normal human emotions by relating how a person perceives himself or herself in relation to the environment and describing how the person is likely to behave in response.

DiSC addresses behavioral responses based on the individual's emotional reaction to a particular environment. This model is not designed to support inferences about what an individual is like at the core of his or her personality or to predict how she or he will behave in the future. Further, it does not attempt to determine how effective the person's behaviors are. Nonetheless, it does offer measurements that can be analyzed when compared with performance data of leaders in a health care organization.

However, it is questioned whether the psychological assessments used, and the results they produce, can be associated with the success of a leader. In order to address this question, data on the results from the DiSC assessment for a small number of senior leaders, 18, of a health care organization are compared to their overall success in that organization. Granted that while the sample is small and the measures for success are not universal, there is evidence to study. Other questions that arise are how do the traits of other organizational leaders compare to senior leadership traits, and are these traits indicators of their individual success. Effectively, in terms of success, does it pay to be like the boss or is it better to differ in your traits?

This initial, exploratory small sample study attempts to determine the answers to these questions and more. If fruitful, larger studies are appropriate. The cost of hiring a leader at the senior level is high and the ability to better screen and select is a valuable capability for the organization.

\section{METHODS}

A dataset containing the results of DiSC profiles for 18 senior leaders administered by the human resources department of a regional health care company was used for this analysis and pilot study. The purpose for collecting the profile information resulting from these DiSC assessments was primarily for use in post-selection executive leadership development. The variables included: whether the individuals were promoted while employed by the organization; the current status of their employment with the organization; and the individual scores from DiSC for the categories of D, I, S, and C for both natural environments and adapted environments. Individual scores were also available for 23 traits that contribute to the determination of the profile scores including the following:

1. Self-Management

2. Goal Achievement

3. Results Orientation

4. Problem Solving

5. Customer Focus

6. Planning and Organization

7. Interpersonal Skills

8. Diplomacy and Tact

9. Conceptual Thinking

10. Decision Making

11. Empathetic Outlook 


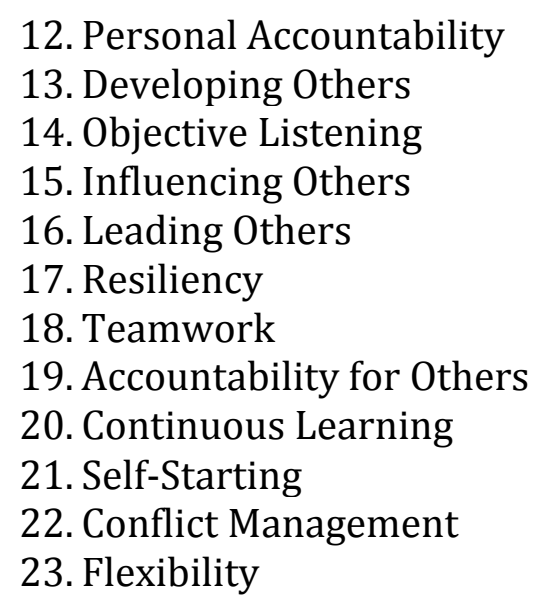

For this research, the variables were analyzed for each of these 23 traits to determine the statistical association. The analysis also restricted itself to the results in the natural environment and not the adapted environment, where stress becomes an influence on leadership behavior. It was felt that normal behavior in a normal environment would be the best analysis since each individual perceives stress in different ways and to different magnitudes. Further research would be appropriate.

\section{FINDINGS}

DiSC scores were compared with two independent outcome variables to assess whether successfully being promoted within the organization (Promoted) or remaining with the company (Positive Employment History) was related to DiSC scores. The two variables for Internally Promoted and Positive Employment History were analyzed for statistically significant associations with these 23 traits. The results revealed a statistically significant association between Internally Promoted and Accountability for Others. The variable Positive Employment History was statistically significant, although negatively related, for five of the 23 trait variables, including those highlighted below:

1. Self-Management

2. Goal Achievement

3. Results Orientation

4. Problem Solving

5. Customer Focus

6. Planning and Organization

7. Interpersonal Skills

8. Diplomacy and Tact

9. Conceptual Thinking

10. Decision Making

11. Empathetic Outlook

12. Personal Accountability

13. Developing Others

14. Objective Listening

15. Influencing Others

16. Leading Others

17. Resiliency

18. Teamwork

19. Accountability for Others

20. Continuous Learning

21. Self-Starting 


\section{Conflict Management}

23. Flexibility

\section{Internally Promoted within the Organization}

Since this is an exploratory study, an alpha level of $\mathrm{p}=0.10$ was used as the cut point for statistical significance. The sample size for the employees measured with the DiSC instrument was 18, and 8 of the subjects in the group had been promoted within the organization. Using SAS version 9.4, the T-Test was used to compare the means for all of the DiSC scores and test for statistical significance, due to the small sample size, was set at the $p=.10$ level.

\section{Accountability for Others and Promoted}

The mean score for Accountability for Others was 7.920 for employees not promoted and 6.963 for employees who were promoted. The difference (1-2) in the mean Accountability for Others score was 0.9575 , the $t$-value was 1.89 , and it was statistically significant at the $p=.0775$ level using pooled variance. The positive difference in the mean between groups indicates positive relationship with Accountability for others and indicates that employees who were internally promoted had higher scores, which could be an indicator of future internal promotability.

\section{Employment History with the Organization}

Since this is an exploratory study, and the sample size is small, an alpha level of $\mathrm{p}=0.10$ was used as the cut point for statistical significance. The sample size for the employees measured with the DiSC instrument was 18, and 14 of the subjects in the group had successful employment with the company until they either retired or left the company positively to pursue a career with another firm. Four employees had a negative Employment History with the company, meaning they left employment under less than favorable conditions. Several of these employees went on to successful careers at other health care companies. Using SAS version 9.4, the T-Test was used to compare the means for all of the DiSC scores with Employment History and test for statistical significance at the $\mathrm{p}=.10$ level.

Table 1 - Traits with Statistical Significance with Positive Employment

\begin{tabular}{|l|l|l|l|l|l|}
\hline \multicolumn{1}{|c|}{ Trait } & $\begin{array}{l}\text { Mean Score w Pos } \\
\text { Employment }\end{array}$ & $\begin{array}{l}\text { Mean Score w Neg } \\
\text { Employment }\end{array}$ & \multicolumn{1}{c|}{$\begin{array}{c}\text { Dif in Mean } \\
\text { Scores }\end{array}$} & t-value & Significance \\
\hline Self-Management & 6.2357 & 7.5250 & -1.2893 & -2.30 & $\mathrm{p}=.0351$ \\
\hline Resiliency & 6.7643 & 7.9500 & -1.1857 & -2.01 & $\mathrm{p}=.0621$ \\
\hline $\begin{array}{l}\text { Continuous } \\
\text { Learning }\end{array}$ & 6.8357 & 7.9500 & -1.1143 & -1.84 & $\mathrm{p}=.0849$ \\
\hline Self-Starting & 6.8643 & 7.9250 & -1.0607 & -1.99 & $\mathrm{p}=.0636$ \\
\hline $\begin{array}{l}\text { Accountability for } \\
\text { Others }\end{array}$ & 7.3286 & 8.0750 & -0.7464 & -1.99 & $\mathrm{p}=.0639$ \\
\hline
\end{tabular}

\section{DISCUSSION}

With regard to the variable Internal Promotion, the positive difference in the mean between groups indicates a positive relationship was found with Accountability for others, and indicates that employees who were internally promoted had higher scores, which could be an indicator of future internal promotability, and internal success.

Concerning the variable of Employment history, relationships with Self-management, Resiliency, Continuous learning, Self-starting, and Accountability for others were all inversely related, negative, and statistically significant. What could explain the inverse relationships that were found to be significantly related with Employment History? Each statistically significant variable will be addressed separately in the list below: 
- Internal Promotions and Accountability for Others - the positive relationship indicates that employees who were Internally Promoted had higher scores, which could be an indicator of future Internal Promotability and success. This may be a relationship that is typically seen with internal promotions and accountability for others, and will be interesting to explore further in larger and varied health care organizations.

- Employment History and Self-management - This implies the desire to control their actions and agenda without a great deal of direction from above. If the lower SelfManagement scoring employees were experiencing career success internally, perhaps those employees with higher Self-Management took advantage of opportunities for success outside the organization.

- Employment History and Resiliency - To be resilient is to recover or bounce back from problems or setbacks. If lower scores were more likely to experience career success internally in the organization, perhaps those with higher Resiliency scores were more comfortable leaving the organization to pursue success externally. Or perhaps the culture of the organization was such that a mistake was difficult to bounce back.

- Employment History and Continuous Learning - The attribute of Continuous Learning is one that most organizations say they desire in their leaders and employees. The idea that lower scoring executives experiencing career success internally might suggest that those who left for external career opportunity and success felt more comfortable that they had the skills to learn, adapt, and be successful in a new environment and organization.

- Employment History and Self-Starting - Normally, those who score higher in this trait are identified as positive contributors to the organization. It may be that in this organization, the lower Self-Starting scores for internal career success by top leadership and higher scores for employees who leave for success opportunities externally is typical behavior with lots of opportunities.

By taking each statistically significant relationship individually and speculating on why the relationships are inversely related, it appears to paint a picture of a health care organization with high turnover rate of 55\% during a booming growth stage of development, with the better employees ultimately leaving the organization to take advantage of other external success opportunities. The CEO of this health care organization must evaluate these findings and answer the basic questions such as:

Do I continue to hire leaders with traits that match these five and know they will do good work while they are with the organization?

Or, do I not hire candidates who match these five traits because they will leave the organization at some point?

Or, do I hire these type candidates and develop a specific retention strategy for them in the hope they will remain longer?

The negative associations with external career changes are all consistent with organizations experiencing high growth rates, high turnover rates in the area of $55 \%$ overall annually, and intense competition for the best human resources. The small sample size for this initial study suggests a need for a larger data set and the collection of qualitative data that can shed more light on these findings. There is further need to determine the results of these analyses in other health care organizations. 


\section{CONCLUSION}

Wagner and Hollenbeck (2015) contend that competitive advantage for an organization is centered on the people selected to lead an organization. In the selection process for leaders of a health care organization, we found that, when considering the number of variables in this pilot study, the limited number of statistically significant variables is disappointing. Leadership success is a complex process and, despite the desire to predict it in the selection process, it is difficult to forecast. Using psychologically based screening tools, such as DiSC, appeals to leaders at the senior levels. Recruiting is expensive, especially at senior levels. The desire to optimize the expense with better selection often leads organizations to attempt to utilize tools beyond their intended uses. While this study did support using accountability for others as a positive indicator of future promotability, the negative relationships for five variables to a lasting positive employability with the organization must be seen as disheartening. All of the variables associated with DiSC are perceived as positive managerial and leadership attributes. The results of this study indicate that a large percentage of leaders with these five positive attributes left the organization. While it may serve to better select future leaders, the idea of selecting candidates with lower scores on six attributes is off-putting. Obviously, more attention is required in this area of research.

\section{References}

Diekmann, J. \& Konig, C. (2015). Personality Testing in Personnel Selection: Love it? Leave it? Understand it!. Psychology Press, Taylor and Francis Group, New York, NY.

Marston, W. (1928). Emotions of Normal People. Routledge, New York, NY.

Ryan, A. \& Ployhart, R. (2014). A Century of Selection. Annual Review of Psychology, 65: 693-717. Annual Reviews, Palo Alto, CA.

Schultz, D. \& Schultz S. (2016). Psychology and Work Today: An introduction to industrial and organizational psychology. Routledge, New York, NY.

Wagner, J. \& Hollenbeck, J. (2015). Organizational Behavior: Securing competitive advantage. Routledge, New York, NY. 